\title{
Seizure Control Among Children on Anti-epileptic Drugs at a Tertiary Hospital in South Western Uganda- A Retrospective Cohort Study
}

Namusisi Jane ( $\sim$ janedaizzie@gmail.com)

Mbarara University of science and technology (MUST)

Kyewalyanga Mike

Mbarara University of science and technology (MUST)

Sabiiti Stephen

Mbarara University of science and technology (MUST)

Murorunkwere Angelique

Mbarara University of science and technology (MUST)

Nantongo Josephine

Mbarara regional referral hospital (MRRH)

Nakibuuka Jane

Makerere University

Martha Sajatovic

University Hospital Case Medical Center, Case Western Reserve University

Kyoyagala Stella

Mbarara University of science and technology (MUST)

Kalubi Peters

Mbarara University of science and technology (MUST)

\section{Research Article}

Keywords: epilepsy, anti-epileptic drugs, children, seizure control, seizure types, comorbidity and adolescence

Posted Date: February 14th, 2022

DOI: https://doi.org/10.21203/rs.3.rs-1284730/v1

License: @ (1) This work is licensed under a Creative Commons Attribution 4.0 International License. Read Full License 


\section{Abstract}

Background: Epilepsy is the commonest neurological disease globally. Up to $70 \%$ of the people with epilepsy can attain good seizure control with appropriate timely diagnosis and treatment, hence better quality of life. However, this is not often achievable in low resource settings.

Aims: This study aimed at determining the seizure control status, describing the factors associated with poor seizure control among children on anti-epileptic drugs (AEDs) for at least six months at MRRH.

Methods: A two stage retrospective cohort study was done. In the first stage, eligible participants were identified and secondary data obtained from their medical records about the baseline social demographics and clinical characteristics at enrollment into the Epilepsy clinic. In the second stage, physical or telephone interview with the care takers were conducted about the current status of the participants. Children below 18 years of age on anti-epileptic drugs for at least six months were consecutive enrolment into this study.

Results: A total of 112 participants were enrolled. Of these, three quarters (75\%) had generalized onset seizures, $23 \%$ had focal onset seizures and $2 \%$ had unknown onset motor seizures. Poor seizure control occurred among 60.4\% (95\% Cl 50.9- 69.9) of the participants. Having a comorbidity ( $\mathrm{p}$-value $0.048 \mathrm{AOR}$ 3.2 (95\% $\mathrm{Cl} 1.0-9.9)$ ), history suggestive of birth asphyxia ( $\mathrm{p}$-value $0.014 \mathrm{AOR} 17.8$ (95\% $\mathrm{Cl} 1.8$ - 176.8)) and being an adolescent (P-value 0.006 , AOR (95\% Cl 1.8-26.6)) were significantly associated with poor seizure control.

Conclusion: The commonest seizure type in our setting were the generalized onset seizures. The proportion with poor seizure control among children on AEDs for at least six months was high. Children with a comorbidity, history suggestive of birth asphyxia at baseline and adolescents were more likely to have poor seizure control and therefore need to be keenly followed up.

\section{Background}

Globally, epilepsy is the commonest neurological disease. It affects over 50 million people of all ages. Up to $80 \%$ of the people with epilepsy live in low- and middle-income countries (1). Worldwide, $0.5 \%$ to $1 \%$ of all children have epilepsy. However, higher prevalence is found among children in rural areas of undeveloped countries at 3.6-44/1000 compared to 3.5-5.5/1000 in developed countries (2). In Uganda, the general prevalence of epilepsy is $10.3 / 1000$ population. The highest peak is among children aged $0-5 y e a r s$ at $30.2 / 1000$ population (3). In South western Uganda, $2 \%$ of the children below $15 y e a r s$ were reported to have the disease (4).

In 2017, the International League Against Epilepsy (ILAE) revised the classification of epilepsy rendering the former classification obsolete $(5,6)$. However, most of the currently available literature is based on the former classification.

Antiepileptic drugs (AEDs) are the mainstay in treatment of epilepsy. With appropriate management, $70 \%$ of people with epilepsy achieve good seizure control and significant reduction in mortality and morbidity (1). This is often not easily achievable in low resource setting. In Uganda, poor seizure control has been reported at as high as $46.8 \%$ among children in care at Mulago National Referral Hospital (MNRH) (7). Seizure control status at six months of treatment can reliably predict long term seizure control and allow for early interventions and referral where need be (8).

Poor seizure control is associated with increased morbidity and mortality among children (9). Among children with epilepsy, seizure control may be influenced by factors like type of seizures, early age at onset, positive family history of epilepsy, type of antiepileptic drug, dose of AEDs, access and adherence to medication, comorbidities existing with epilepsy, and the sleep pattern $(10,11)$.

This study sought to establish the proportion of children on anti-epileptic drugs with poor seizure control and describe its associated factors at the epilepsy clinic, Mbarara Regional Referral Hospital (MRRH). This could enable profiling of children likely to have poor seizure control and hence give them appropriate support early.

\section{Methods}

Study design: This was a two-stage retrospective cohort study of one hundred and twelve children on AEDs attending the Epilepsy clinic at Mbarara Regional Referral Hospital (MRRH) in Mbarara, Uganda.

\section{Setting}

The study was conducted at the Children's Epilepsy Clinic at Mbarara Regional Referral Hospital (MRRH). MRRH is a government owned referral hospital located in Mbarara city along Mbarara-Kabale road, about 260 kilometers from Kampala, the capital city of Uganda. MRRH serves as the regional referral hospital for south-western region of Uganda. It also receives patients from the neighboring regions and countries of Burundi, Democratic Republic of Congo, Rwanda and Tanzania. The hospital has an official bed capacity of 350 beds. It is the teaching hospital for Mbarara University of Science and Technology (MUST) and other health training institutions in the region.

The Pediatric Epilepsy Clinic (PEC) was established by the Government of Uganda in collaboration with Duke Global Health Institute under the Department of Pediatrics and Child Health. The clinic was opened in June 2019 and it runs alongside the Adults Epilepsy Clinic which is conducted on Tuesday by different clinical teams. The PEC is run as a specialized outpatient clinic for children with epilepsy and other neurological disorders on every Wednesday from $0800 \mathrm{hrs}$ to 1600 hrs. Patients are seen by a team comprising of a pediatrician with specialized training in childhood epilepsy and electrical physiology, pediatric residents, medical officer, epilepsy nurses, a data clerk and an EEG Technician. During the COVID-19 pandemic, the SOPs were ensured at the clinic, the staffing remained unchanged but the patient flow reduced significantly. PEC, serves as a referral outpatient clinic for all children aged 2 months to 16 years 
with neurological problems from South Western Uganda and the nearby countries. Some older children between 16 and 18 years who have been in long term management continue to receive care from the PEC in preparation for transition to the adult epilepsy clinic.

The most common diagnosis at the clinic is epilepsy, other conditions seen at the clinic include cerebral palsy, neuro-cutaneous disorders, autism, postinfectious CNS sequel and development delay. About 150 children were seen in the first year of operation. On average, 10 children are seen per clinic day. Services offered by the PEC include clinical evaluation, care and referral to other specialized clinics. Laboratory investigations are done from the outpatient or main hospital laboratories as required. Serum drug levels are not done in the hospital but can be out sourced from private laboratories at a cost of approximately 45USD. Electroencephalogram (EEG) assessment is available within the clinic premises at no cost to the children who require it and are able to follow the instructions. CT scan in available in the hospital at a cost of approximately 70 USD while magnetic resonance imaging (MRI) can only be got from private facilities $260 \mathrm{~km}$ away in Kampala, the capital city of Uganda. These last two are therefore not routinely done.

The children who require routine EEG are booked and get the EEGs done on appointment on Thursday each week. Unscheduled EEGs can be done otherwise in case urgent need arises. Children who require emergency care for epilepsy and/or admission are attended to at the Pediatric Ward where they are reviewed regularly by the same team members that run the PEC. Emergency contacts for the PEC team are available to the patients' attendants to call at any time they have concerns. All the children who attend PEC are registered in the clinic manual register and electronic data system.

The children are triaged by the epilepsy nurse as they arrive at the clinic. Vital signs, weight, height and head circumference measurement are done and recorded on the follow up form and patients note book. The child and care taker then proceed to the clinicians' room where detailed history and examination is done. The diagnosis of epilepsy is mainly clinical. Whenever available, video records, EEG and neuroimaging are utilized in addition. EEGs are done routinely for only patients with clear indications or inconclusive clinical findings as only one machine is available at the hospital for all children and adult patients and only one technician is trained in its use.

Upon diagnosis with epilepsy, a detailed manual up-take form is filled, a clinic number assigned and a file opened for every child. A follow up form is also manually filled and filed at every review visit. The patient's manual file is kept at the clinic. The data on the manual up-take and follow up forms is then entered in the electronic data base daily after the clinic. A summary of clinical notes and prescriptions are made in a note book which the care taker keeps, carries home and brings back to the clinic at every visit. Pre-AEDs counselling is done by the clinicians because for lack of a counsellor or social worker. The care takers are instructed and encouraged to keep seizure diaries for the patient where they record the details of every seizure the child gets including date, time, duration, action taken and the events. A tally sheet in local language is also available for the semi-literate care takers. The seizure diary is reviewed at every visit by the clinician to ascertain the seizure frequency, duration and character. Prescribed drugs are dispensed free of cost to the patient or caretakers at the central hospital pharmacy whenever they are available; the caretakers often have to buy the prescribed medicines from private pharmacies when they are not available in the hospital. The patients and their caretakers are also encouraged to out-source treatment from the public health facilities nearer to their residences.

After the initial enrolment visit and the initiation of care, children are reviewed at two weekly intervals, those who respond well to the AEDs with minimal side effects are then given longer review-intervals of one month, then two or three months' subsequently. Children with poor response to AEDs are thoroughly evaluated for adherence, appropriateness of AEDs given and the appropriate action taken. They are reviewed two weeklies until stable. During the follow-up visits, children are assessed for response to drugs, presence of any adverse drug events. The seizure diary is then reviewed and adjustment in the management plan done accordingly.

Participants: The study included children below 18years with a diagnosis of epilepsy (two or more unprovoked seizures) who had had been receiving care from PEC for at least six months. Only children whose primary caretakers were available physically or reachable phone were included.. Children whose medical records were missing the minimum acceptable data (age, time of enrollment into PEC, diagnosis, telephone contact) were excluded.

Sample size calculation: The sample size was estimated using the Daniel 1999 formula for single population proportion with correction for finite population. It was based on the proportion of poor seizure control among children in MNRH of 46.8\% (7). A sample size of 108 participants was obtained.

Study procedures: This study was approved by Mbarara University of Science and technology Research and Ethics Committee reference MUST-2021-53, received administrative approval from the hospital director of MRRH and study permit from Uganda National Council of Science and Technology reference HS1657ES.

Enrollment and data collection: Eligible study participants were consecutively enrolled into the study from June to August 2021. All medical records for children with epilepsy available at the clinic were assessed for eligibility by the Principal Investigator. Patient information including social demographic data and clinical data including diagnosis, treatment, comorbidity and possible etiological records were abstracted to the questionnaire at enrolment. The telephone contact and identification number were recorded on a different log not the questionnaire. A phone call was then made to the care taker. Verbal informed consent was obtained. Details of the current medical status of the child including seizure frequency, adherence to treatment, current dose and any other information that may have been missing from the medical records was obtained. If all the contacts were not available after several attempts, then the participant was excluded from the study. In case the available telephone contact was not for the primary care taker, a request to access the primary care taker using that or another telephone contact was made. In case the primary care taker was not reachable, then that participant was also excluded.

Also on every clinic day, medical records of all children who came for review were assessed for eligibility by the Principal Investigator. Written Informed consent was obtained from the caretakers of eligible children and emancipated minors, written informed assent was also sought from the children 8years and above with no intellectual disability and physical interviews were conducted. All the methods were performed in accordance with the relevant guidelines and regulations as per the Declaration of Helsinki. 
Standard guidelines for prevention of the spread of COVID-19 were ensured by interviewing the participants and/ or their care takers on phone which enabled data collection with no physical contact or travel. During the physical interviews; alcohol-based hand sanitizer was used before and after reviewing the patient medical records and interviewing every participant, both the interviewer and the interviewee wore face masks as well. The physical interviews were conducted in a spacious well-ventilated room by only the Principal Investigator, research assistant, participant and the one care taker to minimize congestion.

Data management and analysis: All data capture forms were checked for completeness prior to entry, into the database designed using EPI-DATA software version $4 \cdot 2$. Appropriate data cleaning and data verification processes was implemented prior to analysis. The data was then be exported to STATA version 15.0 (College Station, Texas, USA) for further cleaning and analysis

Caretaker and child characteristics were described using means or medians for continuous variables and proportions for categorical variables The proportion of children with epilepsy with poor seizure control was calculated as a fraction of all children enrolled in the study and expressed as a percentage with its corresponding $95 \%$ confidence interval $(\mathrm{Cl})$. Poor seizure control was defined as less than $100 \%$ seizure reduction in seizure frequency from baseline to the time of study in line with the ongoing "Aim for Zero" campaign by the Epilepsy Foundation (12). For the factors associated with poor seizure control. All the factors with $\mathrm{p}$-value $<0.2$ at bivariate analysis those which are biologically plausible with poor seizure control were considered in the multivariate analysis. $\mathrm{A}$ variable was considered significant in this analysis if it had a $p<0.05$.

\section{Results}

Participants' flow and general description: A total of 140 patients/medical records were screened for eligibility, only 28 participants did not meet the inclusion criteria. One hundred and twelve (112) participants were included as shown in Figure1.

The mean age of all the children enrolled was 7.7 years with just over half of them being males (53.6\%). Majority were of Ankole tribe (77.7\%) residing in greater Mbarara (77.7\%) as shown in Table I below.

Table 1: BASELINE SOCIO DEMOGRAPHIC CHARACTERISTICS OF CHILDREN 


\begin{tabular}{|c|c|}
\hline Characteristic & $\mathrm{n}(\%)$ \\
\hline Mean age in years (SD) & $7.7(4.3)$ \\
\hline \multicolumn{2}{|l|}{ Age categories in years } \\
\hline$<5$ & $37(33.0)$ \\
\hline $5-9$ & $43(38.4)$ \\
\hline $10-17$ & $32(28.6)$ \\
\hline \multicolumn{2}{|l|}{ Sex } \\
\hline Male & 60 (53.6) \\
\hline Female & $52(46.4)$ \\
\hline \multicolumn{2}{|l|}{ Tribe } \\
\hline Ankole & $87(77.7)$ \\
\hline Baganda & $9(8.0)$ \\
\hline Bakiga & $8(7.1)$ \\
\hline Others & $8(7.1)$ \\
\hline \multicolumn{2}{|l|}{ Place of residence } \\
\hline Greater Mbarara & $87(77.7)$ \\
\hline Greater Bushenyi & $12(10.7)$ \\
\hline others & $13(11.6)$ \\
\hline \multicolumn{2}{|l|}{ Religion } \\
\hline Catholic & $34(30.4)$ \\
\hline Protestant & $60(53.6)$ \\
\hline Moslem & $7(6.3)$ \\
\hline Pentecostals & $11(9.8)$ \\
\hline \multicolumn{2}{|c|}{ Relationship with the primary care giver } \\
\hline Biological parent & $92(88.4)$ \\
\hline Other relative & $1099.6)$ \\
\hline Sibling & $1(1)$ \\
\hline Foster parent & $1(1)$ \\
\hline
\end{tabular}

The baseline clinical characteristics of the participants are presented in Table 2. Close to a third of the participants had positive family history of epilepsy. The most common identifiable etiology was history suggestive of birth asphyxia followed by previous history of CNS infection and then neonatal jaundice. Majority of the participants had been in care at the clinic for more than one year and about a third of them had been referred to the clinic. Almost half of the participants had associated comorbidity. Sodium valproate was the most frequently used anti-epileptic drug among the children followed by Phenobarbitone, Carbamazepine and Phenytoin respectively. Other less frequently used drugs used were Prednisone, Lamotrigine, and Levetiracetam. Carbamazepine was the most commonly used drug in dual therapy i.e., 5 participants were on carbamazepine and phenobarbitone, 3 on carbamazepine and sodium valproate, 2 on carbamazepine and others, and 2 on sodium valproate and others.

Table 2: Baseline clinical characteristics of the participants 


\begin{tabular}{|c|c|}
\hline CHARACTERISTIC & $\mathrm{n}(\%)$ \\
\hline \multicolumn{2}{|c|}{ Family history if epilepsy } \\
\hline No & $71(63.4)$ \\
\hline Yes & $31(27.7)$ \\
\hline Unknown & $10(8.9)$ \\
\hline \multicolumn{2}{|c|}{ History of febrile seizures } \\
\hline No & $92(82.1)$ \\
\hline Yes & $16(14.3)$ \\
\hline Unknown & $4(3.6)$ \\
\hline \multicolumn{2}{|c|}{ History of neonatal jaundice } \\
\hline No & $96(85.7)$ \\
\hline Yes & $8(7.1)$ \\
\hline Unknown & $8(7.1)$ \\
\hline \multicolumn{2}{|c|}{ History suggestive of CNS infection prior to seizure onset } \\
\hline \multicolumn{2}{|l|}{ No } \\
\hline Yes & $84(75.0)$ \\
\hline \multirow[t]{2}{*}{ unknown } & $14(12.5)$ \\
\hline & $14(12.5)$ \\
\hline \multicolumn{2}{|c|}{ History suggestive of birth asphyxia } \\
\hline \multicolumn{2}{|l|}{ No } \\
\hline Yes & $92(82.1)$ \\
\hline \multirow[t]{2}{*}{ Unknown } & $14(12.5)$ \\
\hline & $6(5.4)$ \\
\hline \multicolumn{2}{|c|}{ History of status epilepticus } \\
\hline No & $66(58.9)$ \\
\hline Yes & $46(41.1)$ \\
\hline \multicolumn{2}{|c|}{ History of head injury } \\
\hline No & 109 (97.3) \\
\hline Yes & $3(2.7)$ \\
\hline \multicolumn{2}{|c|}{ Ever missed clinic visit } \\
\hline No & $34(30.6)$ \\
\hline Yes & $77(69.4)$ \\
\hline \multicolumn{2}{|l|}{ Referral status } \\
\hline No & $68(60.7)$ \\
\hline Yes & $44(39.3)$ \\
\hline \multicolumn{2}{|c|}{ Ever missed any treatment } \\
\hline No & $56(54.4)$ \\
\hline yes & $47(45.6)$ \\
\hline \multicolumn{2}{|l|}{ Duration in care } \\
\hline$<1$ year & $23(20.5)$ \\
\hline 1 year and above & $89(79.5)$ \\
\hline \multicolumn{2}{|c|}{ Associated comorbidities } \\
\hline No & $67(59.8)$ \\
\hline Single & $28(25.0)$ \\
\hline Multiple & $17(15.2)$ \\
\hline
\end{tabular}




\begin{tabular}{|ll|} 
AED regimen & $1(0.9)$ \\
None & $100(90.1)$ \\
Dou-therapy & $9(8.1)$ \\
Tripple therapy & $1(0.9)$ \\
\hline AEDs used & \\
Sodium valproate & $48(42.9)$ \\
Phenobarbitone & $29(25.9)$ \\
Carbamazepine & $32(28.6)$ \\
Phenytoin & $7(6.3)$ \\
Others & $6(5.4)$ \\
\hline Baseline seizure frequency & \\
Daily & $71(63.4)$ \\
Weekly & $12(10.7)$ \\
Monthly & $24(21.4)$ \\
Annually & $10(4.5)$ \\
\hline
\end{tabular}

\section{Common co-morbidities among children with epilepsy at MRRH.}

Forty percent of all the participants had comorbidities associated with epilepsy. Majority of these children had a single comorbidity but about $15 \%$ had multiple. The most common comorbidity identified among children attending the epilepsy clinic was developmental delay/regression, then intellectual disability and cerebral palsy. As shown in by the bar graph in Figure 2. Among others was strabismus, spinal muscular atrophy, insomnia, thyroiditis, amnesia and multiple limb fractures.

Seizure patterns: Basically, three quarters of the children had generalised onset seizures and the rest were focal onset seizures. The expanded classification showed the most frequent type of seizure to be generalized onset motor tonic-clonic seizure, followed by other generalized onset motor seizures and then focal onset motor seizures with no awareness. The least common seizure type was the unknown onset motor seizure as shown in figures 3 and 4 below.

Specific objective two results: Proportion of children with poor seizure control among those under care for at least six months at the Epilepsy clinic, MRRH.

The proportion of participants found with poor seizure control was 60.4 (95\% Cl 50.9- 69.9) as shown in Figure 5 below.

Third specific objective: Factors associated with poor seizure control among children receiving care for at least six months at the Epilepsy clinic, MRRH.

At bivariate analysis; history of febrile seizures, history suggestive of birth asphyxia and presence of comorbidity were significantly associated with poor seizure control as shown in Table 3.

The unadjusted odds of having poor seizure control were almost 10 and 4 times higher among children with history suggestive of birth asphyxia and comorbidity respectively. However, having history of febrile seizure was found protective from poor seizure control with unadjusted odds of 0.3 .

Table 3: RESULTS OF BIVARIATE ANALYSIS FOR FACTORS ASSOCIATED FOR WITH POOR SEIZURE CONTROL. 


\begin{tabular}{|c|c|c|c|c|}
\hline VARIABLE & GOOD SEIZURE CONTROL n (\%) & POOR SEIZURE CONTROL n (\%) & $\begin{array}{l}\text { UNADJUSTED ODDS RATIO } \\
(95 \% \mathrm{Cl})\end{array}$ & P-VALUE \\
\hline \multicolumn{5}{|l|}{ Basic seizure type } \\
\hline Focal onset & $10(38.5)$ & $16(61.5)$ & $1.1(0.4-2.6)$ & 0.888 \\
\hline Generalized onset & $34(40.0)$ & $51(60.0)$ & 1.0 & \\
\hline \multicolumn{5}{|l|}{ Age groups } \\
\hline$<5 y$ & $17(46.0)$ & $20(54.1)$ & 1.0 & 0.133 \\
\hline $5-9 y$ & $19(45.2)$ & $23(54.8)$ & 1.0 & \\
\hline $10-17 y$ & $8(25.0)$ & $24(75.0)$ & $2.5(0.9-7.1)$ & \\
\hline Sex & & & & 0.388 \\
\hline Male & $26(43.3)$ & $34(56.7)$ & 1.0 & \\
\hline Female & $18(35.3)$ & $33(64.7)$ & $1.4(0.7-3.0)$ & \\
\hline \multicolumn{5}{|l|}{ Religion } \\
\hline Catholic & $13(39.3)$ & $20(60.6)$ & $3.8(0.6-22.9)$ & 0.358 \\
\hline Protestant & $22(36.7)$ & $38(63.3)$ & $4.3(0.8-24.2)$ & \\
\hline Moslem & 5 (71.4) & $2(28.6)$ & 1.0 & \\
\hline Pentecostal & $4(36.4)$ & $7(63.6)$ & $4.4(0.5-33.9)$ & \\
\hline \multicolumn{5}{|l|}{ Referred in } \\
\hline No & $27(39.7)$ & $41(60.3)$ & 1.0 & \\
\hline Yes & $17(39.5)$ & $26(60.5)$ & $1.0(0.5-2.2)$ & 0.986 \\
\hline \multicolumn{5}{|l|}{ Duration in care } \\
\hline$<1 y$ & $7(30.4)$ & $16(69.6)$ & 1.0 & \\
\hline 1y and above & $37(42.1)$ & $51(57.9)$ & $0.6(0.2-1.6)$ & 0.311 \\
\hline \multicolumn{5}{|l|}{ Age at seizure onset } \\
\hline$<1 y$ & $10(38.5)$ & $16(61.5)$ & $0.9(0.2-3.9)$ & 0.843 \\
\hline $1-4 y$ & $25(43.1)$ & $33(56.9)$ & $0.8(0.2-2.9)$ & \\
\hline $5-9 y$ & $5(31.3)$ & $11(68.8)$ & $1.3(0.2-6.4)$ & \\
\hline 10-15y & $4(39.4)$ & $7(63.6)$ & 1.0 & \\
\hline \multicolumn{5}{|l|}{ Missed any dose } \\
\hline No & $18(30.5)$ & $41(69.5)$ & 1.0 & \\
\hline Yes & 23. (46.9) & $26(53.1)$ & $0.5(0.2-1.1)$ & 0.080 \\
\hline Missed scheduled clinic visit & & & & 0.555 \\
\hline No & $15(44.1)$ & $19(55.9)$ & 1.0 & \\
\hline Yes & $29(38.2)$ & $47(61.8)$ & $1.3(0.6-2.9)$ & \\
\hline \multicolumn{5}{|l|}{ Relationship with caregiver } \\
\hline Birth parent & $39(42.9)$ & $52(57.1)$ & 1.0 & \\
\hline Other relative & $3(30.0)$ & $7(70.0)$ & $1.75(0.4-7.2)$ & 0.436 \\
\hline Sibling & $0(0.00)$ & $1(100.0)$ & 1.0 & \\
\hline Foster parent & $1(100.0)$ & $0(0.00)$ & 1.0 & \\
\hline \multicolumn{5}{|l|}{ Family history of epilepsy } \\
\hline Yes & $25(35.7)$ & $45(64.3)$ & $0.7(0.3-1.6)$ & 0.524 \\
\hline No & $14(45.2)$ & $17(54.8)$ & 1.0 & \\
\hline Unknown & $5(50.0)$ & $5(50.0)$ & $0.6(0.1-2.1)$ & \\
\hline \multicolumn{5}{|l|}{ History of febrile seizure } \\
\hline No & $31(34.1)$ & $60(65.9)$ & 1.0 & \\
\hline
\end{tabular}




\begin{tabular}{|c|c|c|c|c|}
\hline Yes & $10(62.5)$ & $6(37.5)$ & $0.3(0.1-0.9)$ & 0.034 \\
\hline Unknown & $3(75.0)$ & $1(25.0)$ & $0.2(0.0-1.7)$ & \\
\hline \multicolumn{5}{|c|}{ History of neonatal jaundice } \\
\hline No & $38(40.0)$ & $57(60.0)$ & 1.0 & \\
\hline Yes & $2(25.0)$ & $6(75.0)$ & $2.0(0.4-10.4)$ & 0.583 \\
\hline Unknown & $4(50.0)$ & $4(50.0)$ & $0.7(0.2-2.8)$ & \\
\hline History of CNS infection & & & & 0.684 \\
\hline No & $32(38.6)$ & $51(61.5)$ & 1.0 & \\
\hline Yes & $5(35.7)$ & $9(64.3)$ & $1.1(0.8-3.7)$ & \\
\hline Unknown & $7(50.0)$ & $7(50.0)$ & $0.6(0.2-2.0)$ & \\
\hline \multicolumn{5}{|c|}{ History suggestive of birth asphyxia } \\
\hline \multicolumn{5}{|l|}{ No } \\
\hline Yes & $39(42.9)$ & $52(57.1)$ & 1.0 & \\
\hline \multirow[t]{2}{*}{ Unknown } & $1(7.1)$ & $13(92.9)$ & $9.7(1.2-77.7)$ & 0.015 \\
\hline & $4(66.7)$ & $2(33.3)$ & $0.3(0.1-2.2)$ & \\
\hline \multicolumn{5}{|c|}{ History of status epilepticus } \\
\hline No & $29(44.6)$ & $36(55.4)$ & 1.0 & \\
\hline Yes & $15(32.6)$ & $31(67.4)$ & $1.7(0.8-3.7)$ & 0.203 \\
\hline \multicolumn{5}{|l|}{ Presence of comorbidity } \\
\hline No & $33(50.0)$ & $33(50.0)$ & 1.0 & \\
\hline Single & $6(21.4)$ & $22(78.6)$ & $3.7(1.3-10.2)$ & 0.023 \\
\hline Multiple & $5(29.4)$ & $12(70.6)$ & $2.4(0.8-7.6)$ & \\
\hline History of head injury & & & & 0.332 \\
\hline No & $42(38.9)$ & $66(61.1)$ & 1.0 & \\
\hline Yes & $2(66.7)$ & $1(33.3)$ & 1.0 & \\
\hline
\end{tabular}

At multivariate logistic regression analysis model, history suggestive of birth asphyxia and presence of comorbidity and being an adolescent were significantly associated with poor seizure control as shown in Table 4 below.

The adjusted odds of having poor seizure control were almost 18,7 and 3 times higher among children with history suggestive of birth asphyxia, the adolescents and those with a single comorbidity respectively.

Table 4: RESULTS OF MULTIVARIATE LOGISTIC ANALYSIS FOR FACTORS ASSOCIATED WITH POOR SEIZURE CONTROL. 


\begin{tabular}{|lll|}
\hline VARIABLE & $\begin{array}{l}\text { ADJUSTED ODDS RATIO } \\
(95 \% \mathrm{Cl})\end{array}$ & P-VALUE \\
\hline Basic seizure type & & \\
Focal onset & $1.2(0.4-3.7)$ & 0.776 \\
Generalized onset & 1.0 & \\
Sex & & \\
Male & 1.0 & 0.654 \\
Female & $1.2(0.5-3.0)$ & \\
\hline Age groups & & 0.166 \\
$<5 y$ & 1.0 & 0.006 \\
5-9y & $2.3(0.7-7.3)$ & \\
10- 17y & $6.8(1.8-26.6)$ & 0.229 \\
\hline Age at seizure onset & & 0.176 \\
$<1 y$ & $4.74(0.37-59.93)$ & 0.252 \\
1-4y & $3.91(0.54-28.27)$ & \\
$5-9 y$ & $3.68(0.40-34.30)$ & 0.048 \\
10-15y & 1.0 & 0.014 \\
\hline History suggestive of birth asphyxia & & 0.175 \\
No & 1.0 & \\
Yes & $17.8(1.8-176.8)$ & \\
Unknown & $0.3(0.0-1.8)$ & \\
\hline Presence of comorbidity & & \\
No & 1.0 & \\
Single & $3.2(1.0-9.9)$ & \\
Multiple & $2.7(0.6-12.8)$ & \\
\hline
\end{tabular}

\section{Discussion}

This study set out to determine the seizure control status and describe the factors associated with poor seizure control among children who been attending the Pediatrics Epilepsy Clinic at MRRH for at least 6 months.

We found that almost two thirds of the children having poor seizure control among children with epilepsy at MRRH. This was similar to the $72 \%$ poor seizure control reported by Jang et al Republic of Guinea (13). However, its much higher than one third poor seizure control reported by WHO (14) and about two fifths reported at Mulago National Referral Hospital and in Scotland $(7,15)$. The higher proportion of poor seizure control in this cohort could be because we considered the strictest ILAE outcome scale (class one definition -completely seizure free; on auras) while both the studies done at MNRH and in Scotland used class 3 ILEA definition. Also, the high proportions of children with history of status epilepticus and those who have ever missed clinic appointment or dose of AEDs could have contributed to the poor seizure control. Furthermore, MRRH catchment area is largely rural which could be contributing to challenges in accessing AEDs and medical services. This could have been worsened by the fact that we did this study during total country lockdown due to COVID-19 hence worsened seizure control. Limited investigative capacity including neuroimaging and serum drug levels at MRRH could also be contributing to the high proportion of poor seizure control because of inability to objectively monitor drug intake.

Factors associated with poor seizure control among children receiving care for at least six months from the MRRH epilepsy clinic.

Among children with epilepsy attending the MRRH clinic for at least 6 months, poor seizure control was significantly associated with history suggestive of birth asphyxia, presence of comorbidity at baseline and being an adolescent. These have consistently been found significantly associated with poor seizure control in other studies including a retrospective study done in Turkey and prospective study done in Nepal $(16,17)$

History suggestive of birth asphyxia: Birth asphyxia is one of the most common cause of acquired structural abnormalities of the brain in LMIC like Uganda and that increases the risk factor of intractable seizures $(6,18)$ Adverse perinatal events were also found to be associated with active convulsive epilepsy among children in a community based study done in eastern Uganda (19).

Adolescence: Being an adolescent was significantly associated with poor seizure control, this could be due to the endocrine, emotional and psychological issues related to this age groups resulting into sleep deprivation, alcohol use or other drugs, defaulting on medication and stigma. All these contribute to poor 
seizure control (20). A recent study done in this same setting reported high prevalence of stigma among children with epilepsy especially adolescents (21).

Presence of comorbidity: Presence of comorbidity in patients with epilepsy is known to worsen morbidity, prognosis and seizure control (6).

However, other factors like early age at seizure onset, seizure type, positive family history and polytherapy were not found significant in our study $(7,10,11,16$, 17). In a retrospective cohort study done in Turkey, early age at onset (below one year), multiple seizures in a day, diagnosis of specific syndrome of epilepsy, history of neonatal seizure and status epilepticus, symptomatic etiology, microcephaly, presence of motor or mental deficiency or delay were found significantly associated with intractable seizure while having generalized seizures was protective (16).

Strength of the study: Our study had a representative sample size which increases its internal and external validity. Being a retrospective cohort study with both primary and secondary data, we were able to minimize missing data, obtain informed consent and also follow up participants for six months retrospectively.

Limitations: The incomplete medical records. Some of the telephone contacts were not be available online at the time of data collection despite several attempts. Some of the available telephone contacts could not be used to access the primary care taker.

Only convulsive seizures as reported by the care taker were considered which is subject to recall bias and uncertainty.

\section{Conclusion}

1. The proportion of children with poor seizure control among those with epilepsy in south western Uganda months is high compared to reports from central Uganda and WHO.

2. Presence of a comorbidity, having history suggestive of birth asphyxia at baseline and being an adolescent were significantly associated with poor seizure control among children in south western Uganda.

We therefore recommend that the clinician should assess all children with epilepsy for presence of comorbidity and history suggestive of birth asphyxia. Children with epilepsy that have a comorbidity and those with history suggestive of birth asphyxia should be closely followed up to ensure appropriate seizure control.

Clinicians and guardians should also closely follow up the adolescents to optimize seizure control. Adolescent friendly services like peer support groups and counselling could help improve their seizure control status.

Larger prospective cohort studies are recommended to identify, classify and explore the exact effect of birth asphyxia, adolescence and comorbidity on seizure control among children in our setting.

\section{Abbreviations}

AEDs- Anti-epileptic Drugs

PEC- Pediatric Epilepsy Clinic

MRRH- Mbarara Regional Referral Hospital

MNRH- Mulago National Referral Hospital

\section{Declarations}

Ethics approval: This study was approved by Mbarara University of Science and technology Research and Ethics Committee reference MUST-2021-53, received administrative approval from the hospital director of MRRH and study permit from Uganda National Council of Science and Technology reference HS1657ES.

Consent of participants: Written or verbal Informed consent was obtained from the caretakers of eligible children and emancipated minors, written informed assent was also sought from the children 8years and above with no intellectual disability before interviews were conducted. All the methods were performed in accordance with the relevant guidelines and regulations as per the Declaration of Helsinki.

Consent for publication: Parents/ legal guardians provided written informed consent for publication in a peer review journal.

Availability of data and material: The datasets used and analyzed during the current study are available in the supplementary file attached named "RAW DATA- EPILEPSY.

Competing interest: We hereby declare that neither the authors nor the funders of this research project have any relationship constituting a conflict of interest.

Funding: This research project was funded by the first mile project through Mbarara University of Science and Technology and the National Institute of Neurological Disorders and Stroke and Stroke of the National Institute of Health under award number R01NS118544. The content is solely the responsibility of the authors and does not necessarily represent the official views of the National Institute of Health. 
Author's contributions: Conceived and designed the study: Namusisi Jane (NJ), Kyoyagala Stella (KS), Kalubi Peters (KP), Nantongo Josephine (NnJ). Performed the study: NJ; Analysed the data: NJ, KS, KP, Kyewalyanga Mike (KM), Sabiiti Stephen (SS), Murorunkwere Angelique (MA); Critical manuscript review; NJ, KS, KP, NnJ, KM, SS, MA, Nakibuuka Jane (NkJ) and Martha Sajatovic (MS). All authors read read and approved the final manuscript.

Acknowledgements: The authors are very grateful to the Epilepsy clinic, department of Pediatrics and Child Health, Mbarara University of Science and Technology and the funders for the support and enabling this study. We are also grateful and indebted to all our participants and their caretakers who endured our lengthy interviews.

\section{References}

1. WHO. Epilepsy fact sheets: World Health Organisation; 2019 [updated 20 June 2019.

2. Camfield P, Camfield C. Incidence, prevalence and aetiology of seizures and epilepsy in children. Epileptic Disord. 2015;17(2):117-23.

3. Kakooza-Mwesige A, Ndyomugyenyi D, Pariyo G, Peterson SS, Waiswa PM, Galiwango E, et al. Adverse perinatal events, treatment gap, and positive family history linked to the high burden of active convulsive epilepsy in Uganda: A population-based study. Epilepsia Open [Internet]. 2017 2017/06//; 2(2):[188-98 pp.]. Available from: http://europepmc.org/abstract/MED/29588948 https://doi.org/10.1002/epi4.12048 https://europepmc.org/articles/PMC5719853 https://europepmc.org/ $\mathrm{pdf}=$ render.

4. Duggan MB. Epilepsy in rural Ugandan children: seizure pattern, age of onset and associated findings. African health sciences. 2010;10(3):218-25.

5. Fisher RS, Cross JH, French JA, Higurashi N, Hirsch E, Jansen FE, et al. Operational classification of seizure types by the International League Against Epilepsy: Position Paper of the ILAE Commission for Classification and Terminology. Epilepsia. 2017;58(4):522-30.

6. Scheffer IE, Berkovic S, Capovilla G, Connolly MB, French J, Guilhoto L, et al. ILAE classification of the epilepsies: Position paper of the ILAE Commission for Classification and Terminology. Epilepsia. 2017;58(4):512-21.

7. Atugonza R, Kakooza-Mwesige A, Lhatoo S, Kaddumukasa M, Mugenyi L, Sajatovic M, et al. Multiple anti-epileptic drug use in children with epilepsy in Mulago hospital, Uganda: a cross sectional study. BMC Pediatr [Internet]. 2016 2016/03//; 16:[34 p.]. Available from: http://europepmc.org/abstract/MED/26961364 https://doi.org/10.1186/s12887-016-0575-

0 https://europepmc.org/articles/PMC4785653 https://europepmc.org/articles/PMC4785653?pdf=render.

8. Xia L, Ou S, Pan S. Initial Response to Antiepileptic Drugs in Patients with Newly Diagnosed Epilepsy As a Predictor of Long-term Outcome. Frontiers in Neurology. 2017;8(658).

9. Nickels KC, Grossardt BR, Wirrell EC. Epilepsy-related mortality is low in children: A 30-year population-based study in Olmsted County, MN. Epilepsia. 2012;53(12):2164-71.

10. Wilmshurst JM, Kakooza-Mwesige A, Newton CR. The Challenges of Managing Children With Epilepsy in Africa. Seminars in Pediatric Neurology. 2014;21(1):36-41.

11. Kothare SV, Kaleyias J. Sleep and epilepsy in children and adolescents. Sleep Med. 2010;11(7):674-85.

12. Institute EFS. About Seizure Control EPILEPSY FOUNDATION2017 [cited 2020.

13. Jang M, Sakadi F, Tassiou NR, Abass CF, Grundy SJ, Woga A, et al. Impact of poorly controlled epilepsy in the Republic of Guinea. Seizure. 2018;61:71-7. 14. WHO. EPILEPSY: WORLD HEALTH ORGANISATION; 2019 [updated 20 JUNE 2019; cited 2020. FACT SHEET].

15. Kwan P, Brodie MJ. Early identification of refractory epilepsy. N Engl J Med. 2000;342(5):314-9.

16. Seker Yilmaz B, Okuyaz C, Komur M. Predictors of Intractable Childhood Epilepsy. Pediatric Neurology. 2013;48(1):52-5.

17. Poudel P, Chitlangia M, Pokharel R. Predictors of Poor Seizure Control in Children Managed at a Tertiary Care Hospital of Eastern Nepal. Iranian Journal of Child Neurology. 2016;10(3):48-56.

18. Ba-Diop A, Marin B, Druet-Cabanac M, Ngoungou EB, Newton CR, Preux PM. Epidemiology, causes, and treatment of epilepsy in sub-Saharan Africa. Lancet Neurol. 2014;13(10):1029-44.

19. Kakooza-Mwesige A, Ndyomugyenyi D, Pariyo G, Peterson SS, Waiswa PM, Galiwango E, et al. Adverse perinatal events, treatment gap, and positive family history linked to the high burden of active convulsive epilepsy in Uganda: A population-based study. Epilepsia Open. 2017;2(2):188-98.

20. MD JWWMJIS. ABOUT TEENS WITH EPILEPSY EPILEPSY FOUNDATION 2013 [updated AUGUST 272013.

21. Kirabira J, Nakawuki M, Fallen R, Zari Rukundo G. Perceived stigma and associated factors among children and adolescents with epilepsy in south western Uganda: A cross sectional study. Seizure. 2018;57:50-5.

\section{Figures}




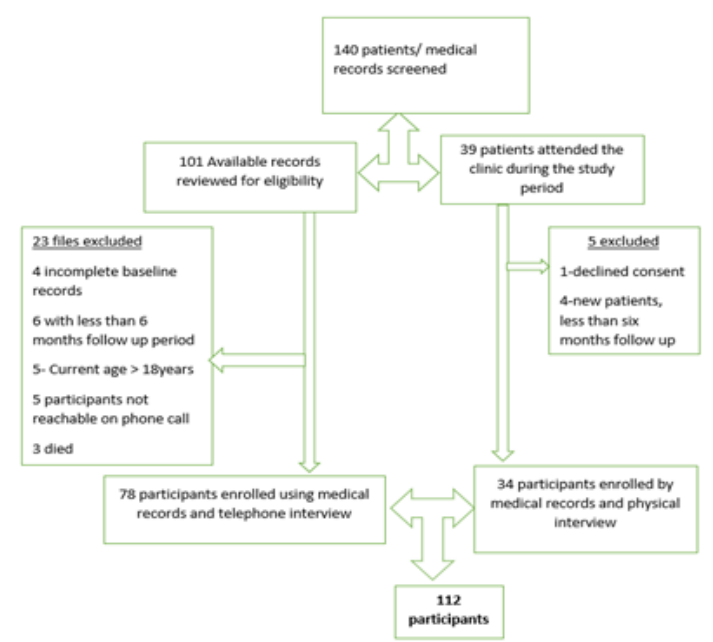

Figure 1

PARTICIPANT FLOW CHART

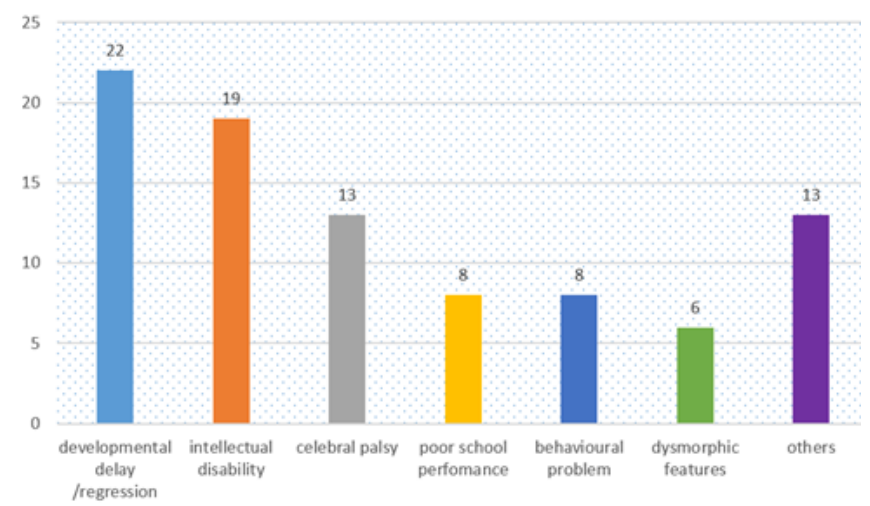

Figure 2

Bar graph representing comorbidities among children with epilepsy at MRRH

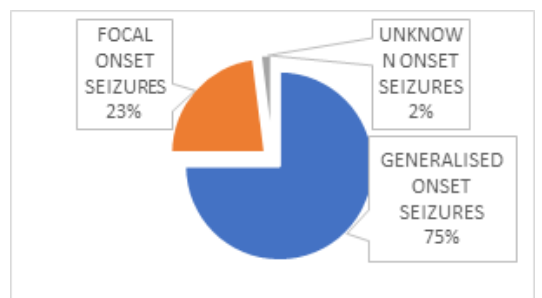

\section{Figure 3}

PIE CHART SHOWING BASIC SEIZURE TYPE DISTRIBUTION AMONG CHILDREN ATTENDING THE EPILEPSY CLINIC FOR AT LEAST SIX MONTHS AT MRRH.

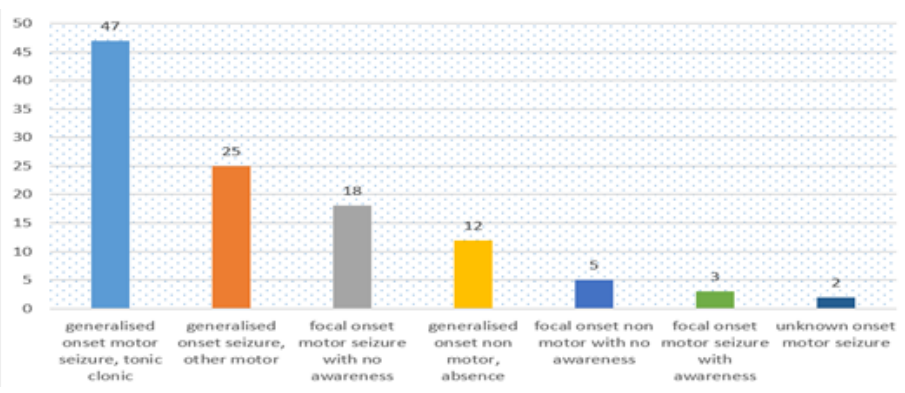


Figure 4

Bar graph showing the expanded classification seizure type frequency among children attending the epilepsy clinic at MRRH for at least six months.

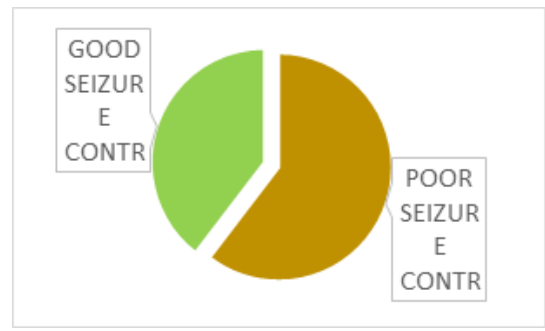

\section{Figure 5}

Pie-chart representing the proportion of poor seizure control among the participants. 